\title{
Influence of age on the relation between heart rate variability, left ventricular ejection fraction, frequency of ventricular extrasystoles, and sudden death after myocardial infarction
}

\author{
Olusola Odemuyiwa, Thomas G Farrell, Marek Malik, Yaver Bashir, Teri Millane, \\ Tim Cripps, Jan Poloniecki, D Bennett, A John Camm
}

\begin{abstract}
Aims-To examine the influence of age on the prediction of sudden death after acute myocardial infarction based on heart rate variability (HRv), left ventricular ejection fraction (LVEF), and the frequency of ventricular extrasystoles.

Background-Autonomic and left ventricular function and the frequency of ventricular extrasystoles change with age but the influence of age on the prediction of sudden death from these variables has not been examined.
\end{abstract}

Methods-The 477 patients who had been through an early postinfarction risk stratification protocol and followed up for a mean of 790 days were dichotomised at 60 years of age.

Results-Sudden deaths occurred with similar frequency in both age groups (12 $(4 \cdot 7 \%)$ of the 256 patients aged $<60$ years and seven $(3 \cdot 2 \%)$ of the 221 older patients). Sudden death, however, accounted for $52 \%$ of all deaths in the young group but only $18.4 \%$ of all deaths in the older group $(p<0.01)$. An HRv index of $<20$ units combined with an average of more than 10 ventricular extrasystoles an hour on Holter monitoring (VE10) had a sensitivity of $50 \%$, a positive predictive accuracy of $33 \%$, and a risk ratio of 18 in the young group (p $<0.001)$ but was not significantly predictive in older patients. The situation was similar when the combination of an LVEF $<40 \%$ with VE10 was considered. This combination had a sensitivity of $44 \%$, positive predictive accuracy of $36.4 \%$, and a risk ratio of $16 \cdot 1$ in young patients $(p<0.001)$, but was not significantly predictive in older patients. The combination of VE10 with either LVEF $<40 \%$ or HRv $<20$ units gave a sensitivity of $75 \%$, positive predictive accuracy of $30 \%$, and a risk ratio of 30 in young patients $(p<0.001)$, but the relation between this combination and sudden death in older patients was not statistically significant.

Conclusion-In postinfarction patients aged $<60$ sudden death was a more predominant mode of death and was more reliably predicted from a depressed HRv index, an LVEF $<40 \%$, and VE10 than in older postinfarction patients. These findings may have important implications for post-infarction risk stratification and management.

Left ventricular dysfunction and frequent ventricular extrasystoles are associated with an increased risk of sudden death after myocardial infarction. ${ }^{12}$ The clinical value of this relation, however, is still questioned partly because it is unclear how these variables cause sudden death. The association between autonomic dysfunction and ventricular fibrillation in animals ${ }^{3}$ has recently generated interest in the potential of autonomic function tests to predict and explain sudden death in postinfarction patients. Firstly, Kleiger et $a l^{4}$ showed that depressed heart rate variability was associated with increased all cause mortality after myocardial infarction and $\mathrm{La}$ Rovere $e t a l^{5}$ and Farrell et $a l^{6}$ subsequently showed a correlation between reduced baroreceptor sensitivity and an increased risk of sudden death and ventricular arrhythmias in postinfarction patients.

There is a decline in autonomic function with age in both postinfarction patients and in healthy controls. ${ }^{7-9}$ Age is also a well recognised determinant of all cause mortality after myocardial infarction. ${ }^{10-12}$ But as autonomic function, ${ }^{7-9}$ ventricular systolic, ${ }^{13}$ and diastolic function, ${ }^{14-16}$ and the prevalence of frequent ventricular extrasystoles ${ }^{17}$ all change with age, their value as predictors of sudden death may well change with age. We examined the practical implications of this hypothesis by dichotomising 477 serial postinfarction patients at 60 years of age.

\section{Patients and methods}

PATIENTS

The study population consisted of 477 patients under the age of 75 years admitted to our institution with acute myocardial infarction. Acute myocardial infarction was diagnosed if two of three criteria were met:

(a) Characteristic chest pain lasting 30 minutes. (b) A sequential rise and fall in plasma concentrations of aspartate transaminase, $\beta$ hydroxy- 
butyric dehydrogenase, or creatine kinase with a peak concentration at least twice the upper limit of the reference range of our laboratory.

(c) Development of new pathological $Q$ waves or persistent ST-T changes suggestive of non$Q$ wave infarction.

Only patients admitted straight from home and who survived the acute phase of myocardial infarction were enrolled in the study and studied prospectively.

\section{EVALUATION}

As part of the risk stratification protocol, the patients' historical and clinical data on admission were recorded and following tests were performed between five and 11 days after infarction:

(a) Ambulatory 24 hour electrocardiographic recordings with a Reynolds Tracker two channel recorder (leads II and CM5). We used the Pathfinder 3 system, an operator-computer interactive device, for arrhythmia recognition and grading ventricular frequency.

(b) Patients performed a symptom limited treadmill exercise test with the Bruce protocol just before discharge from hospital. Exerciseinduced ST segment depression, angina, or ventricular tachycardia; a rise in systolic blood pressure of less than $30 \mathrm{~mm} \mathrm{Hg}$; or an inability to complete the first stage of the protocol were indications for predischarge left ventriculography and selective coronary angiography. Left ventricular ejection fraction (LVEF) was calculated from the ventricular silhouettes at end systole and end diastole in the right anterior oblique view by a digitising personal computer program (MAC angio computer package) based on the formula of Sandler and Dodge. ${ }^{18}$ In those patients who did not undergo coronary angiography, radionuclide angiograms were performed in the supine position and the LVEFs were calculated by the multiple gated method performed in the $45^{\circ}$ left anterior oblique projection. ${ }^{19}$

\section{FOLLOW UP}

All patients were followed up in a special infarct clinic. Follow up visits were made three to four weeks after discharge from hospital, then at three months, and subsequently every year or more frequently when clinically indicated. Treatment was at the discretion of

Table 1 Clinical and historical characteristics and distribution of prognostic variables

\begin{tabular}{|c|c|c|c|}
\hline & $A g e<60(n=256)$ & $A g e \geqslant 60(n=221)$ & p Value \\
\hline \multicolumn{4}{|c|}{ Clinical and historical characteristics ( $n(\%)$} \\
\hline $\begin{array}{l}\text { Past MI } \\
\text { Anterior MI } \\
\text { Non-Q wave MI } \\
\text { Streptokinase } \\
\text { Aspirin } \\
\beta \text { blockers on discharge } \\
\text { Revascularisation }\end{array}$ & $\begin{array}{c}21(8 \cdot 2) \\
120(46 \cdot 9) \\
103(40 \cdot 2) \\
112(43 \cdot 8) \\
119(46 \cdot 5) \\
110(43 \cdot 0) \\
66(25 \cdot 8)\end{array}$ & $\begin{array}{r}45(20 \cdot 4) \\
98(44 \cdot 3) \\
75(34 \cdot 0) \\
94(42 \cdot 5) \\
109(49 \cdot 3) \\
58(26 \cdot 2) \\
39(17 \cdot 7)\end{array}$ & $\begin{array}{l}\mathbf{p}<0.001 \\
p<0.001 \\
p<0.05\end{array}$ \\
\hline \multicolumn{4}{|c|}{ Distribution of prognostic variables } \\
\hline $\begin{array}{l}\text { Age }(y(\text { SEM })) \\
\text { HRv < } 20(\text { no }(\%)) \\
\text { HRv }(\text { mean }(\text { SEM })) \\
\text { LVEF < 40\% }(\mathrm{n}(\%)) \\
\text { LVEF }(\text { mean }(\text { SEM }) \\
\text { VE10 }(\text { n }(\%))\end{array}$ & $\begin{array}{l}51 \cdot 1(0 \cdot 43) \\
40(17 \cdot 9) \\
28 \cdot 8(0 \cdot 71) \\
51(21 \cdot 9) \\
51 \cdot 8(0 \cdot 9) \\
38(17 \cdot 0)\end{array}$ & $\begin{array}{l}66(0 \cdot 25) \\
63(32 \cdot 3) \\
24 \cdot 8(0 \cdot 8) \\
62(30 \cdot 5) \\
47 \cdot 5(1 \cdot 1) \\
55(28 \cdot 2)\end{array}$ & $\begin{array}{l}\mathrm{p}<\mathbf{0 . 0 0 1} \\
\mathbf{p}<\mathbf{0 . 0 0 0 1} \\
\mathbf{p}<\mathbf{0 . 0 5} \\
\mathbf{p}<\mathbf{0 . 0 0 4} \\
\mathbf{p}<\mathbf{0 . 0 1}\end{array}$ \\
\hline
\end{tabular}

the patient's physician. $\beta$ Blockers and antiarrhythmic therapy were not routinely prescribed. The main endpoint was sudden death, which was classified by $O O$ and TF without knowledge of the risk stratification results. Sudden death was defined as death within an hour of the onset of new symptoms: it included instantaneous deaths, deaths during sleep, and unwitnessed death, provided these occurred within an hour of the patient last being seen. ${ }^{20}$ It was confirmed by examination of the case records, by the results of necropsy when available, and by interviewing the relatives or the general practitioner.

\section{ANALYSIS}

A heart rate variability index (HRv) was calculated by digitising the 24 hour electrocardiographic recording off line and transferring it to a personal computer (IBM PC-AT). Each beat was then classed as normal or aberrant based on the matching pairs principle. An HRv was calculated for each patient. ${ }^{2122}$ The frequency distribution of durations of normal to normal RR intervals was constructed. Measured values of $H R v$ were then obtained in technical units by measuring the baseline width of the distribution curve. This method of triangular interpolation of the frequency distribution of the normal to normal interval duration, which has been explained in more detail elsewhere, ${ }^{2324}$ is not affected by low levels of noise and artefact, whereas the widely used methods based on the standard deviation of normal to normal interval durations require the long term electrocardiogram to be clear of artefacts. ${ }^{21}$

To show the strength of associations we selected a LVEF cut off of $40 \%$. Previous studies have shown a close association between a frequency of ventricular extrasystoles of $\geqslant 10$ per hour (VE10) and sudden death. ${ }^{12}$ A cut off point of 20 baseline width units was selected for the HRv because our previous study had shown that this value best distinguished patients with arrhythmic events from those without. ${ }^{24}$ The population was divided at the age of 60 because this gave nearly the same number of patients and the same rates of sudden death in each group.

The HRv was calculated in 418 patients; left ventricular angiography carried out in 436 patients; and 409 patients had data for both. Predictive characteristics were calculated for the appropriate subtotals.

The $\chi^{2}$ test with Yates' correction and $t$ tests was used to determine the significance of the differences between proportions and means respectively. A value of $p<0.05$ was considered to be significant.

\section{Results}

There were $343(71.9 \%)$ men and $134(28 \cdot 1 \%)$ women aged between 26 and 75 (mean (SD), $57.6(9.4)$ years. Of the 477 patients, 221 were 60 or older and 256 were younger than 60 . A higher proportion of older patients $(20.4 \%)$ than younger patients $(8.2 \%)$ had a history of previous infarction $(p<0.001)$ but more 
Table 2 Relation between clinical variables and sudden death (n (sudden deaths))

\begin{tabular}{lrr}
\hline & Age $<60$ & Age $\geqslant 60$ \\
\hline Past MI & $21(3)$ & $45(1)$ \\
Anterior MI & $120(4)$ & $98(5)$ \\
Non-Q-wave MI & $103(6)$ & $75(2)$ \\
Streptokinase & $112(2)$ & $94(2)$ \\
Killip $>2$ & $10(0)$ & $32(4)$ \\
Congestive failure & $12(1)$ & $33(2)$ \\
$\beta$ blockers on discharge & $110(1)$ & $58(1)$ \\
HRv < 20 units & $40(6)$ & $63(5)$ \\
LVEF < 40\% & $51(5)$ & $62(2)$ \\
VE10 & $38(6)$ & $55(2)$ \\
HR $>80 /$ min & $202(7)$ & $168(5)$ \\
\hline
\end{tabular}

See footnote to table 1 for abbreviations.

younger $(43 \%)$, than older patients $(26.2 \%)$ were discharged on $\beta$ blockers $(p<0.01$ ). Tables 1 and 2 show the other major historical and clinical characteristics.

\section{ALL CAUSE MORTALITY AND SUDDEN DEATH \\ RATES}

The mean follow up period was 790 (range 490-1412) days during which there were 61 $(12 \cdot 8 \%)$ deaths, made up of $23(9 \%)$ of the 256 younger patients and $38(17 \cdot 2 \%)$ of the 221 older patients $(\mathrm{p}<0.02)$. There were $19(4 \%)$ sudden deaths, made up of $12(4.7 \%)$ of 256 in the young group, and seven $(3 \cdot 2 \%)$ of the 221 older patients (NS). Therefore, $12(52 \%)$ of the 23 deaths in the young group and seven $(18.4 \%)$ of the 38 deaths in the older group were sudden $(\mathrm{p}<0.01)$.

TIMING OF SUDDEN DEATHS

Sudden deaths in younger patients occurred between seven and 373 days after infarction; seven $(58.3 \%)$ occurred within 30 days of infarction. The sudden deaths in older patients occurred between 18 and 439 days of infarction with three $(42 \%)$ occurring within 30 days of infarction.

Table 3 Relation of HRv and VE10 to sudden death

\begin{tabular}{|c|c|c|c|c|c|c|}
\hline & $n$ & $S d$ & sens & $p p a$ & $(95 \% C I)$ & p Value \\
\hline \multicolumn{7}{|c|}{ All patients $(n=418)$, sudden deaths $=14(3 \cdot 3 \%)$} \\
\hline $\begin{array}{l}\mathrm{HRv}<20 \\
\mathrm{VE} 10 \\
\mathrm{HRv}<20+\mathrm{VE} 10\end{array}$ & $\begin{array}{r}103 \\
93 \\
35\end{array}$ & $\begin{array}{r}11 \\
8 \\
5\end{array}$ & $\begin{array}{l}78 \cdot 6 \\
57 \cdot 0 \\
36 \cdot 0\end{array}$ & $\begin{array}{r}10 \cdot 7 \\
8 \cdot 6 \\
14 \cdot 3\end{array}$ & $\begin{aligned} 11 \cdot 0 & (3 \cdot 2 \text { to } 39 \cdot 3) \\
4 \cdot 7 & (3 \cdot 1 \text { to } 24 \cdot 1) \\
6 \cdot 1 & (2 \cdot 2 \text { to } 17 \cdot 3)\end{aligned}$ & $\begin{array}{l}<0.001 \\
<0.01 \\
<0.01\end{array}$ \\
\hline \multicolumn{7}{|c|}{ Patients aged $<60(n=223)$, sudden deaths $=8(3.6 \%)$} \\
\hline $\begin{array}{l}\mathrm{HRv}<20 \\
\operatorname{VE} 10 \\
\operatorname{HRv}<20+\mathrm{VE} 10\end{array}$ & $\begin{array}{l}40 \\
38 \\
12\end{array}$ & $\begin{array}{l}6 \\
6 \\
4\end{array}$ & $\begin{array}{l}75 \cdot 0 \\
75 \cdot 0 \\
50 \cdot 0\end{array}$ & $\begin{array}{l}15 \cdot 0 \\
15 \cdot 8 \\
33 \cdot 0\end{array}$ & $\begin{array}{l}13.7(2.9 \text { to } 65.4) \\
15.4(3.2 \text { to } 73.0) \\
17.6 \quad(5.0 \text { to } 62.2)\end{array}$ & $\begin{array}{l}<0.001 \\
<0.001 \\
<0.001\end{array}$ \\
\hline \multicolumn{7}{|c|}{ Patients aged $\geqslant 60(n=195)$, sudden deaths $=6(3 \cdot 1 \%)$} \\
\hline $\begin{array}{l}\mathrm{HRv}<20 \\
\mathrm{VE} 10 \\
\mathrm{HRv}<20+\mathrm{VE} 10\end{array}$ & $\begin{array}{l}63 \\
55 \\
23\end{array}$ & $\begin{array}{l}5 \\
2 \\
1\end{array}$ & $\begin{array}{l}83 \cdot 3 \\
33 \cdot 0 \\
16 \cdot 7\end{array}$ & $\begin{array}{l}7 \cdot 9 \\
3 \cdot 6 \\
4 \cdot 3\end{array}$ & $\begin{array}{r}10.5(1.3 \text { to } 88.2) \\
2.6(0.5 \text { to } 13.9) \\
1.4(0.2 \text { to } 11.5)\end{array}$ & $\begin{array}{l}<0.05 \\
\text { NS } \\
\text { NS }\end{array}$ \\
\hline
\end{tabular}

Sd, sudden deaths; ppa, positive predictive accuracy; rr, risk ratio; sens, sensitivity.

Table 4 Relation of EF $<40$ and VE10 to sudden death

\begin{tabular}{|c|c|c|c|c|c|c|}
\hline & $n$ & $S d$ & Sens & $p p a$ & $(95 \% C I)$ & p Value \\
\hline \multicolumn{7}{|c|}{ All patients $(n=436)$, sudden deaths $=15(3.4 \%)$} \\
\hline $\begin{array}{l}\text { LVEF }<40 \\
\text { LVEF }<40+\text { VE10 }\end{array}$ & $\begin{array}{r}113 \\
37\end{array}$ & $\begin{array}{l}7 \\
5\end{array}$ & $\begin{array}{l}46 \cdot 7 \\
33 \cdot 0\end{array}$ & $\begin{array}{r}6 \cdot 2 \\
13 \cdot 5\end{array}$ & $\begin{array}{ll}2.5 & (1.0-6 \cdot 8) \\
5.4 & (2 \cdot 0-14 \cdot 3)\end{array}$ & $\begin{array}{l}\text { NS } \\
<0.01\end{array}$ \\
\hline \multicolumn{7}{|c|}{ Patients aged $<60(n=233)$, sudden deaths $=9(3.9 \%)$} \\
\hline $\begin{array}{l}\text { LVEF }<40 \\
\text { LVEF }<40+\text { VE10 }\end{array}$ & $\begin{array}{l}51 \\
11\end{array}$ & $\begin{array}{l}5 \\
4\end{array}$ & $\begin{array}{l}55 \cdot 6 \\
44 \cdot 4\end{array}$ & $\begin{array}{r}9 \cdot 8 \\
36 \cdot 4\end{array}$ & $\begin{array}{rr}4.5 & (1 \cdot 3-16 \cdot 0) \\
16 \cdot 1 & (3 \cdot 9-69 \cdot 4)\end{array}$ & $\begin{array}{l}<0.05 \\
<0.001\end{array}$ \\
\hline \multicolumn{7}{|c|}{ Patients aged $\geqslant 60(n=203)$, sudden deaths $=6(2.9 \%)$} \\
\hline $\begin{array}{l}\text { LVEF }<40 \\
\text { LVEF }<40+\text { VE10 }\end{array}$ & $\begin{array}{l}62 \\
26\end{array}$ & $\begin{array}{l}2 \\
1\end{array}$ & $\begin{array}{l}33 \cdot 3 \\
16 \cdot 7\end{array}$ & $\begin{array}{l}3 \cdot 2 \\
3 \cdot 8\end{array}$ & $\begin{array}{ll}1 \cdot 1 & (0 \cdot 2-6 \cdot 0) \\
1 \cdot 4 & (0 \cdot 2-11 \cdot 2)\end{array}$ & $\begin{array}{l}\text { NS } \\
\text { NS }\end{array}$ \\
\hline
\end{tabular}

For abbreviations see footnotes to tables 1 and 3 .
RELATION BETWEEN AN HRV INDEX $<20$ UNITS AND SUDDEN DEATH

An HRv index $<20$ units was found in 40 $(17.9 \%)$ of the young patients: six (15\%) of these 40 compared with two $(1 \%)$ of the 183 patients with $\mathrm{HRv}>20$ units died suddenly ( $\mathrm{p}<0.001)$. An HRv $<20$ units was found in $63(32.3 \%)$ of the older patients: five $(7 \cdot 9 \%)$ of these 63 compared with one $(1 \%)$ of the 132 older patients with HRv $>20$ units died suddenly $(\mathrm{p}<0.05)$ (table 3$)$.

\section{RELATION BETWEEN A LOW LVEF AND SUDDEN} DEATH

An LVEF $<40 \%$ was found in $51(21.9 \%)$ of the 233 younger patients: five $(10 \%)$ of these 51 compared with four $(2 \%)$ of the 182 patients with $\mathrm{EF} \geqslant 40 \%$ died suddenly $(\mathrm{p}<0.05)$. An $\mathrm{EF}<40 \%$ was found in $62(30.5 \%)$ of the 203 older patients: two $(3 \cdot 2 \%)$ of these 62 compared with four $(2.8 \%)$ of the 141 patients with $\mathrm{EF} \geqslant 40 \%$ died suddenly (NS) (table 4 ).

\section{RELATION BETWEEN VE10 AND SUDDEN DEATH}

Thirty eight $(17 \%)$ of 223 young patients had VE 10: six $(15 \cdot 8 \%)$ of these 38 died suddenly compared with two (1\%) of the remaining 185 patients $(p<0.001)$. VE10 was found in 55 $(28.2 \%)$ of the older patients: two $(3.6 \%)$ of these 55 patients and four $(2.9 \%)$ of the remaining patients died suddenly (NS) (table 3).

RELATION BETWEEN THE COMBINATION OF VE10 AND HRV AND SUDDEN DEATH

A low HRv and VE10 were combined in 12 $(5.4 \%)$ of the young patients: four $(33 \%)$ of these 12 patients died suddenly compared with four $(1.6 \%)$ of the remaining patients $(p<0.001)$. The relation between these variables and sudden death in older patients was not statistically significant (table 3 ).

RELATION BETWEEN SUDDEN DEATH AND THE COMBINATION OF A LOW LVEF AND VE10 An LVEF $<40 \%$ was combined with VE10 in $11(4.7 \%)$ of the young patients: four $(36.4 \%)$ of these died suddenly compared with five $(2.3 \%)$ of the remaining patients $(p<0.001)$. The relation between this combination of variables and sudden death in the older group did not reach statistical significance (table 4).

RELATION BETWEEN SUDDEN DEATH AND THE COMBINATION OF VE10 WITH LOW HRV OR LOW LVEF

A combination of VE10 with either a low HRv or an LVEF $<40 \%$ was found in $20(9 \cdot 1 \%)$ of the 236 young patients: six $(30 \%)$ of these 20 died suddenly compared with two $(1 \%)$ of the remaining patients $(p<0.001)$ (table 5$)$. The relation between this combination of variables and sudden death did not reach statistical significance in the older group.

\section{Discussion}

We have shown that sudden death is a commoner mode of death and is more reliably 
Table 5 Relation of LVEF and HRv to sudden death ( $S d$ )

\begin{tabular}{|c|c|c|c|c|c|c|}
\hline & $n$ & $S d$ & Sens & $p p a$ & $(95 \% C I)$ & p Value \\
\hline \multicolumn{7}{|c|}{ All patients $(n=409)$, sudden deaths $=14(3.4 \%)$} \\
\hline $\begin{array}{l}\mathrm{HRv}+\mathrm{EF} \\
\mathrm{HRv} / \mathrm{EF} \\
\mathrm{HRv} / \mathrm{EF}+\mathrm{VE} 10\end{array}$ & $\begin{array}{r}42 \\
174 \\
52\end{array}$ & $\begin{array}{r}5 \\
13 \\
7\end{array}$ & $\begin{array}{l}35 \cdot 7 \\
92 \cdot 8 \\
50 \cdot 0\end{array}$ & $\begin{array}{r}11 \cdot 9 \\
7 \cdot 5 \\
13 \cdot 5\end{array}$ & $\begin{aligned} 4.9 & (1 \cdot 8-14.0) \\
17.6 & (2 \cdot 3-131 \cdot 6) \\
6.9 & (5 \cdot 0-36 \cdot 6)\end{aligned}$ & $\begin{array}{l}<0.01 \\
<0.001 \\
<0.001\end{array}$ \\
\hline \multicolumn{7}{|c|}{ Patients aged $<60(n=219)$, sudden deaths $=8(3.7 \%)$} \\
\hline $\begin{array}{l}\mathrm{HRv}+\mathrm{EF} \\
\mathrm{HRv} / \mathrm{EF} \\
\mathrm{HRv} / \mathrm{EF}+\mathrm{VE} 10\end{array}$ & $\begin{array}{l}12 \\
79 \\
20\end{array}$ & $\begin{array}{l}3 \\
8 \\
6\end{array}$ & $\begin{array}{r}37.5 \\
100.0 \\
75.0\end{array}$ & $\begin{array}{l}25 \cdot 0 \\
10 \cdot 0 \\
30 \cdot 0\end{array}$ & $\begin{array}{l}\frac{10 \cdot 4}{30}(2 \cdot 6-41 \cdot 3) \\
(16 \cdot 5-138 \cdot 4)\end{array}$ & $\begin{array}{l}<0.01 \\
<0.001 \\
<0.001\end{array}$ \\
\hline \multicolumn{7}{|c|}{ Patients aged $>60(n=190)$, sudden deaths $=6(3 \cdot 2 \%)$} \\
\hline $\begin{array}{l}\mathrm{HRv}+\mathrm{EF} \\
\mathrm{HRv} / \mathrm{EF} \\
\mathrm{HRv} / \mathrm{EF}+\mathrm{VE} 10\end{array}$ & $\begin{array}{l}30 \\
95 \\
32\end{array}$ & $\begin{array}{l}2 \\
5 \\
1\end{array}$ & $\begin{array}{l}33.0 \\
83 \cdot 3 \\
16 \cdot 7\end{array}$ & $\begin{array}{l}6 \cdot 7 \\
5 \cdot 3 \\
3 \cdot 1\end{array}$ & $\begin{array}{ll}2 \cdot 7 & (0 \cdot 5-14 \cdot 2) \\
5 \cdot 0 & (2 \cdot 0-49 \cdot 4) \\
1 \cdot 0 & (0 \cdot 1-8 \cdot 2)\end{array}$ & $\begin{array}{l}\text { NS } \\
\text { NS } \\
\text { NS }\end{array}$ \\
\hline
\end{tabular}

See footnotes to tables 1 and 3 for abbreviations.

predicted in younger than in older postinfarction patients by heart rate variability, frequency of ventricular extrasystoles, and to a lesser extent the left ventricular ejection fraction. Our first finding is consistent with previous reports. Vismara $e t$ al $^{25}$ who found that $36 \%$ of the deaths in postinfarction patients aged under 50 years but only $16 \%$ of the deaths in older patients were sudden. According to Daly et al $46 \%$ of deaths in 551 young men who survived unstable angina or acute myocardial infarction were sudden and the proportion of sudden deaths was inversely related to age at initial attack. ${ }^{26}$

The rates of sudden death $(4 \%, 5 \cdot 4 \%$, and $4.5 \%$ ) in our study and in the MILIS and BHAT studies are similar. ${ }^{12}$ The higher proportion of patients with VE10 in our study $(22 \%)$, however, compared with $15 \%$ and $13 \%$ reported by the MILIS and BHAT studies may be due to differences between the studies in criteria for patient recruitment, in the timing of Holter monitoring, and in the proportion of older patients. ${ }^{12}$ The positive predictive accuracy of VE10 for sudden death in the present study of $8.6 \%$ was, nevertheless, close to the $10 \%$ and $9 \%$ reported by the MILIS and BHAT studies. ${ }^{12}$

The BHAT study found a direct relation between the frequency of ventricular extrasystoles and age; but the implications of this finding for risk stratification were not considered. ${ }^{3}$ We found VE10 to be a more reliable predictor of sudden death in the younger patients (table 3). The combination of low HRv with VE10 was present in $8.5 \%$ of our patients and was also a much better predictor in the younger group (table 3 ).

An LVEF $<40 \%$ had a positive predictive accuracy for sudden death of $6 \cdot 2 \%$ in our study and of $10 \%$ in the MILIS study. ${ }^{1}$ In a report in 1977 by Schulze et $a l,{ }^{27} 55 \%$ of the patients (compared with $26 \%$ in our study) had an LVEF $<40 \%$, a finding that had a positive predictive accuracy of $18 \%$. In the study by Schulze $e t$ al all the sudden deaths occurred in patients with an LVEF $<40 \%$. But a rate of $14.7 \%$ for sudden deaths in patients taking quinidine or procainamide, compared with $6.4 \%$ in those not taking antiarrhythmic drugs, indicates that the relation between LVEF $<40 \%$ and sudden death may have been reinforced by the concomitant arrhythmogenic effect of antiarrhythmic therapy in patients with low ejection fractions.
In the MILIS study $40(7 \cdot 5 \%)$ patients had both VE10 and a low LVEF. ${ }^{1}$ This subgroup was older than the other subgroups of patients and contained $24 \%$ of all the sudden deaths. If, however, older patients are more likely than younger patients to have frequent ventricular extrasystoles and to have had a previous infarction (and thus low LVEFs) the predictive characteristics of these variables may have been different in the younger members of this high risk subgroup. In our study about $5 \%$ of young patients had a low LVEF and VE10 and this combination had a sensitivity of $44 \%$ and a positive predictive accuracy of $36 \%$. We also found that the combination of VE10 and a depressed $\mathrm{HRv}$ and the combination of VE10 with an LVEF $<40 \%$, though they had similar predictive characteristics, identified different patients at high risk of sudden death (tables 3 and 4). Even more striking was that the combination of VE10 with either low HRv or an LVEF $<40 \%$ had a sensitivity of $75 \%$ and a positive predictive accuracy of $30 \%$ in young patients, and values of only $17 \%$ and $3 \%$ in the older group (table 5).

Our results may reflect the inadequacies of present techniques. Thus even if all the sudden deaths were due to autonomic dysfunction, the degree to which depressed heart rate variability accurately reflects this dysfunction seems to decline with age. This may be due to a considerable age related divergence between the effects of autonomic dysfunction on the sinus node and on the electrophysiology of the myocardium.

Our findings may also be the result of a decline with age in the proportion of sudden deaths caused by autonomic dysfunction. There are several possible mechanisms for this proposition:

(a) If the predisposition to ventricular fibrillation is brought about by the change in autonomic tone, rather than absolute autonomic level, older patients may experience less severe changes in sympathovagal balance after myocardial infarction than younger patients.

(b) Sympathetic denervation is associated with adrenergic hypersensitivity and an increased predisposition to ventricular fibrillation in dogs. ${ }^{28}$ Preconditioning ischaemia prevents this sympathetic denervation. Subclinical ischaemia caused by more severe coronary disease and to decreased myocardial compliance ${ }^{28}$ may have a similar protective effect in older patients. Also young patients have higher $\beta$ receptor density and activity and less myocardial fibrosis than older patients ${ }^{29} 30$ and may therefore be either more likely, for the same degree of sympathovagal imbalance, to reach the rapid rates at which ventricular tachycardia deteriorates into ventricular fibrillation or to reach such rates more quickly. ${ }^{31}$

(c) The relative importance of thromboembolic, rheological, ischaemic, and haemodynamic causes of sudden death increases with age. $^{32}$

\section{CLINICAL IMPLICATIONS}

Whatever their explanation, our results indicate that it is not correct to assume 
physiological homogeneity in a postinfarction population. Such an approach will lead to young patients at higher risk of sudden death being overlooked and many older patients receiving inappropriate treatment.

\section{LIMITATIONS OF THE STUDY}

The dichotomy point of 60 years seems arbitrary and its physiological significance is unclear. It was chosen, however, because it provided nearly the same proportion of patients and the same rates of sudden death in each group. The relations between heart rate variability, frequency of ventricular extrasystoles, and sudden death remained significant even in patients younger than 55, among whom there was a sudden death rate of only $2.4 \%$. Our use of VE10 as a prognostic variable was based on the results of previous studies, ${ }^{12}$ but this variable may need to be refined: ventricular extrasystoles caused by increased sympathetic activity may have different prognostic implications from those triggered by increased wall stress. The LVEF may be refined by considering diastolic function and abnormalities of wall motion.

Only two of the 12 young and one of the seven older patients who died suddenly were taking $\beta$ blockers but because $\beta$ blocker therapy was uncontrolled its effect on our results is difficult to determine. The rates of sudden death may have been lower had more patients $\geqslant 60$ received $\beta$ blockers. ${ }^{33}$ The effect of thrombolytic therapy on our results and the effect of the difference in the proportion of young and old patients who had surgery or angioplasty is also unknown.

Nevertheless, we have shown that age influenced the prediction of sudden death after myocardial infarction based on autonomic function tests, left ventricular ejection fraction, and the frequency of ventricular extrasystoles. If confirmed, our findings could have significant implications for postinfarction risk stratification and management.

This work was supported by the British Heart Foundation.

1 Mukharji J, Rude R, Poole W, and the Milis Study Group Risk factors for sudden death after acute myocardia infarction. Two-year follow-up. Am J Cardiol 1984 54:31-6.

2 Kostis JB, Byington R, Friedman LM, Goldstein S, Furber C, for the BHAT Study Group. Prognostic significance of ventricular ectopic activity in survivors of acute myocardial infarction. J Am Coll Cardiol 1987;10:231-42.

3 Schwartz PJ, Vanoli E, Stramba-Badiale M, De Ferrari G, Billman G, Foreman DR. Autonomic mechanisms and sudden death. New insights from analysis of baroreceptor reflexes in conscious dogs with and without a myocardial reflexes in conscious dogs with and with

4 Kleiger RE, Miller PJ, Bigger JT, Moss A, and the Multicentre Postinfarction Research Group. Decreased Multicentre Postinfarction Research Group. Decreased
heart rate variability and its association with increased heart rate variability and its association with increased
mortality after acute myocardial infarction. Am J Cardiol mortality after acute

5 La Rovere MT, Specchia G, Mortara A, Schwartz PJ. Baroreflex sensitivity. Clinical correlates, and cardiovascular mortality among patients with a first myocardia infarction. A prospective study. Circulation 1988;78: 816-24.

6 Farrell TG, Paul V, Cripps TR, Bennett ED, Ward D Camm AJ. Baroreflex sensitivity and electrophysiological correlates in postinfarction patients. Circulation 1991, 83:945-52.

7 Gribbin B, Pickering T, Sleight P, Peto R. Effect of age and high blood pressure on baroreflex sensitivity in Man. Circ Res 1971;29:424-31.

8 Collins K, Exton-Smith A, James M, Oliver D. Functional changes in autonomic nervous responses with ageing. Age Ageing 1980;9:17-24

9 Ingall TJ, McLeod J, O'Brien PC. The effect of ageing on autonomic nervous system function. Aust $N Z \mathrm{~J}$ Med 1990;20:570-7.

10 Martin C, Thompson P, Armstrong B, Hobbs M, DeKlerk $\mathrm{N}$. Long-term prognosis after recovery from myocardial infarction: a nine year follow up of the Perth Coronary Register. Circulation 1983;68:961-9.

11 Tofler G, Muller J, Stone P, Willich S, Davis V, Poole K, et al and the MILIS study group. Factors leading to shorter survival after acute myocardial infarction in patients aged 65 to 75 years compared with younger patients. Am J 65 to 75 years compared
Cardiol $1988 ; 62: 860-7$.

12 Peart I, Odemuyiwa O, Albers C, Hall A, Kelly C, Hall RJC. Exercise testing soon after myocardial infarction; its relation to course and outcome at one year in patients aged less than 55 years. Br Heart J 1989;61:231-7.

13 Port S, Cobb FR, Coteman FE, Jones RH. Effect of age on the response of the left ventricular ejection fraction to exercise. N Engl J Med 1980;303:1133-7.

14 Iskrandian AS, Hakki A. Age-related changes in left ventricular diastolic performance. Am Heart $J 1986 ; 112: 75-8$.

15 Hodkinson HM, Pomerance A. The clinical significance of senile cardiac amyloidosis-a prospective clinico-pathological study. $Q J$ Med 1977; 46:381-7.

16 Gestenblith G, Fredriksen J, Yui FC, Fortuin NJ, Lakatta EG, Weisfeldt MC. Echocardiographic assessment of a normal adult aging population. Circulation 1977;56: 273-8.

17 Kostis J, McCrone K, Moreyra A, Gotzoyannis S, Aglitz N, Natarajan $\mathrm{N}$, et al. Premature ventricular complexes in the absence of identifiable heart disease. Circulation 1981; 63:1351-6.

18 Sandler $\mathrm{H}$, Dodge $\mathrm{H}$. The use of single plant angiocardiograms for the calculation of left ventricular volume in man. Am Heart J 1968;75:325-34.

19 Bigger J, Fleiss J, Kleiger R, Miller J, Rolnitzky L, and the Multicentre Post-Infarction Research Group. The relationships among ventricular arrhythmias left ventricular dysfunction, and mortality in the 2 years after myocardial infarction. Circulation 1984;69:250-8.

20 Greene H, Richardson D, Barker A, Roden D, Capone R, Echt D, Friedman L, Gillespie M, Hallstrom A, Verter J, and the Cardiac Arrhythmia Pilot Study Investigators. Classification of deaths after myocardial infarction as Classification of deaths after myocardial infarction as
arrhythmic or nonarrhythmic. Am J Cardiol 1989;63:1-6.

21 Malik M, Farrell T, Cripps T, Camm AJ. Heart rate variability in relation to prognosis after myocardial infarcvariability in relation to prognosis after myocardial infarc-
tion: Selection of optimal processing techniques. Eur tion: Selection of optimal

22 Cripps T, Malik M, Farrell T, Bennett DE, Ward D, Camm AJ. Clinical application of a new method for quantification of heart rate variability in acute myocardial infarction patients: performance in comparison with other prognostic indicators. Br Heart J 1991;65:14-19.

23 Odemuyiwa O, Malik M, Farrell T, Bashir Y, Poloniecki J, Camm AJ. Comparison of the predictive characteristics of heart rate variability index and left ventricular ejection fraction for all cause mortality, arrhythmic events and sudden death after acute myocardial infarction. $A m$ Cardiol 1991;68:434-9.

24 Farrell T, Bashir Y, Cripps T, Bennett E, Ward D, Camm AJ. A simple method of risk stratification for arrhythmic events based on heart rate variability and signal-averaged electrocardiogram. J Am Coll Cardiol (in press).

25 Vismara L, Amsterdam E, Mason D. Relation of ventricular arrhythmias in the late hospital phase of acute myocardial arrhythmias in the late hospital phase of acute myocardial
infarction to sudden death after hospital discharge. $\mathrm{Am} \mathrm{J}$ infarction to sudden

26 Daly L, Hickey L, Graan I, Mulcahy R. Predictors of sudden death up to 18 years after a first attack of unstable angina or myocardial infarction. $B r$ Heart $J$ 1987;58 567-71

27 Schulze R, Strauss H, Pit B. Sudden death in the year following myocardial infarction: relation to ventricular premature contractions in the late hospital phase and left ventricular ejection fraction. Am J Med 1977;62:192-9.

28 Miyazaki T,Zipes D. Protection against autonomic denervation following acute myocardial infarction by preconditioning ischaemia. Circ Res 1989;54:437-48.

29 O'Malley K, Docherty JR, Kelly JB. Adrenoceptor status and cardiovascular function in ageing. $J$ Hypertens 1988; 6:59-62.

30 Kelly J, O'Malley K. Adrenoceptor function and ageing. Clin Sci 1984;66:509-16.

31 Leclercq JF, Maisonblanche P, Cauchemez B, Coumel P. Respective role of sympathetic tone and of cardiac pauses Respective role of sympathetic tone and of cardiac pauses in the genesis of 62 cases of ventricular fibrillation recorded

32 Stevenson WG, Linssen GC, Havenith MG, Brugada $P$ Wellens HJ. The spectrum of death after myocardial Wellens HJ. The spectrum of death after myocardial infarction:

33 Gundersen T, Abrahamsen AA, Kjekshus J, Ronnevik PK, for the Norwegian Multicentre Study Group. Timololrelated reduction in mortality and reinfarction in patients aged 65-75 years surviving acute myocardial infarction. Circulation 1982;66:1179-84. 